\section{(6) OPEN ACCESS}

\title{
Proteinase 3-antineutrophil cytoplasmic antibody-positive ulcerative colitis presenting with abducens neuropathy
}

\author{
Yuki Kirito, Daisuke Yamamoto, Tsuyoshi Uchiyama
}

Department of Neurology, Seirei Hamamatu General Hospital, Hamamatsu, Shizuoka, Japan

\section{Correspondence to} Dr Daisuke Yamamoto; daisuke-yama@sis.seirei.or.jp

Accepted 23 December 2016

\section{SUMMARY}

A 72-year-old man with ulcerative colitis (UC) presented with complete left abducens nerve palsy. Although MRI showed no significant changes, cerebrospinal fluid analysis revealed pleocytosis and elevated protein and interleukin (IL)-6 levels. His serum proteinase 3-antineutrophil cytoplasmic antibody (PR3-ANCA) level was also elevated to $31.1 \mathrm{U} / \mathrm{mL}$, but granulomatosis with polyangiitis was not observed. On the basis of the diagnosis of autoimmune cranial neuropathy, he was treated with steroid therapy. While tapering steroid therapy, his serum PR3-ANCA levels; cerebrospinal fluid findings, including IL-6 levels; and symptoms improved. Serum PR3-ANCA could be a useful parameter of neurological disorders associated with ANCA-positive UC.

\section{BACKGROUND}

The association of ulcerative colitis (UC) with antineutrophil cytoplasmic antibodies (ANCAs) has been studied. ANCA testing is helpful in distinguishing UC from Crohn's disease. ${ }^{1}{ }^{2}$ Although UC-associated ANCAs do not have the potential for development of systemic vasculitis or for neutrophil activation, ${ }^{3}$ the pathogenic role of ANCAs in inflammatory bowel diseases remains unknown. It is also unknown whether the ANCA level shows simultaneous changes with UC disease activity. We describe a case of unilateral abducens nerve palsy associated with proteinase 3 (PR3)-ANCA-positive UC, where serum PR3-ANCA levels and neurological symptoms improved simultaneously during the course of tapering steroid therapy.

\section{CASE PRESENTATION}

A 72-year-old man with a 5-year history of UC was referred to our hospital reporting double vision that had started 40 days previously. Since his UC symptoms were unresponsive to steroid therapy, he was treated with vedolizumab and his UC was stable on admission to our hospital. Clinical examination revealed complete left abducens nerve palsy, with no evidence of uveitis and a normal fundus. No other abnormal neurological findings were detected. His temperature was normal.

\section{INVESTIGATIONS}

His C reactive protein $(2.2 \mathrm{mg} / \mathrm{dL})$ and PR3-ANCA (31.1 U/mL; ELISA) levels were elevated. Cerebrospinal fluid (CSF) analysis revealed pleocytosis $\left(25 / \mathrm{mm}^{3}\right)$, elevated protein $(127 \mathrm{mg} / \mathrm{dL})$ and interleukin (IL)-6 (437 pg/mL) levels, and normal glucose and intracranial pressure levels. Results of extensive microbiological and immunological studies were normal. Antibodies and antigens for HIV were negative. CT of the chest, abdomen and pelvis were unremarkable, except for findings of UC. Brain MRI showed a swollen nasal cavity mucosal membrane and no significant change in the left abducens nerve and around it (figure 1). Magnetic resonance angiography showed no stenotic lesions. Nasal cavity mucosal membrane biopsy showed no specific changes and no evidence of granuloma. There was no evidence of granulomatosis with polyangiitis, and the lungs and kidneys were normal.

\section{TREATMENT}

On the basis of diagnosis of autoimmune cranial mononeuritis of the abducens nerve, high-dose methylprednisolone $(1000 \mathrm{mg} /$ day $)$ steroid therapy was initiated intravenously and continued for 3 days (figure 2). The left abducens nerve palsy partially improved; therefore, another course of high-dose methylprednisolone steroid therapy was continued followed by oral prednisolone $(20 \mathrm{mg} /$ day $)$ steroid therapy.

\section{OUTCOME AND FOLLOW-UP}

Two months from its onset, the left abducens nerve palsy along with CSF findings had improved. During the course of tapering steroid therapy, serum PR3-ANCA and CSF IL-6 (1.2 pg/mL) levels decreased. Four months after the onset, the left abducens nerve palsy had completely resolved with the treatment of oral prednisolone $(10 \mathrm{mg} /$ day $)$.

\section{DISCUSSION}

We report a case of unilateral abducens nerve palsy associated with PR3-ANCA-positive UC caused by autoimmune mechanisms. Neurological disorders associated with UC are uncommon, although other extraintestinal manifestations have been described. Neurological disorders have been reported in 3\% of cases with inflammatory bowel disease, ${ }^{4}$ and only a few cases of cranial neuropathy associated with UC have been reported (table 1). ${ }^{5-9}$ Some cases of olfactory dysfunction, optic neuritis and sensorineural hearing loss have been reported.

Biological therapies may cause neurological complications. Central nervous system vasculitis secondary to anti-tumour necrosis factor therapy has been reported, including other diseases. ${ }^{4}$ The safety of vedolizumab with respect to neurological 


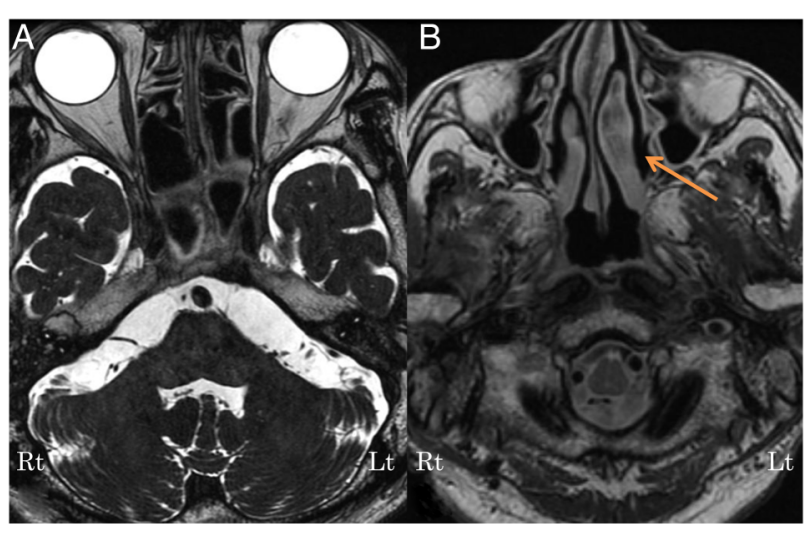

Figure 1 (A) $\mathrm{T}_{2}$-weighted axial (1.5 T; TR, $3160 \mathrm{~ms}$; TE, $183.3 \mathrm{~ms}$ ) images show no significant changes in the left abducens nerve or around it. (B) $\mathrm{T}_{2}$-weighted axial (1.5 T; TR, $4025 \mathrm{~ms}$; TE, $88.4 \mathrm{~ms}$ ) images showed a swollen nasal cavity mucosal membrane (arrow).

complications for UC has been evaluated. ${ }^{10}$ Our patient developed abducens nerve palsy 10 months after initiating vedolizumab therapy. His neurological symptoms improved with steroid therapy without cessation of the vedolizumab, but the possibility of an association with vedolizumab in the present case cannot be excluded.

Pathophysiologically, three major mechanisms are reported to cause neurological disorders associated with UC: (i) cerebrovascular disease as a consequence of thrombosis and thromboembolism, (ii) systemic and cerebral vasculitis and (iii) probably immune-mediated neuropathy and cerebral demyelination. ${ }^{11}$ There are no reports about CSF IL-6 levels in neurological complications associated with UC; however, simultaneous improvement of neurological symptoms along with decreasing CSF IL-6 levels and responsiveness to steroid therapy suggests inflammatory and autoimmune mechanisms in our patient.

It is interesting that the serum PR3-ANCA level; CSF findings, including the IL-6 level; and neurological symptoms showed simultaneous improvement during the course of tapering steroid therapy in the present case. Clinical implications of PR3-ANCA levels in UC have not been defined. It has been suggested that the serum PR3-ANCA level could be a useful serological diagnostic marker for UC, ${ }^{1}{ }^{2}$ but it is not known whether or not the PR3-ANCA level and UC disease activity show simultaneous changes. Neurological disorders associated with UC may occur independent of the UC activity. ${ }^{4} 11{ }^{12}$ In our case, neurological symptoms developed independent of the UC disease activity, and the serum PR3-ANCA levels and neurological symptoms showed simultaneous improvement, indicating that the serum PR3-ANCA level may have been a useful parameter of the neurogenic complications accompanying ANCA-positive UC in the present case.

We described a case of unilateral abducens nerve palsy associated with PR3-ANCA-positive UC where serum PR3-ANCA levels and neurological symptoms improved simultaneously during the course of tapering steroid therapy. Serum PR3-ANCA and CSF IL-6 levels appeared to be useful parameters of neurogenic complications in this patient. More studies are needed to define the role of PR3-ANCA in UC.
Figure 2 Two courses of high-dose methylprednisolone (1000 mg/day for 3 days) were initiated intravenously followed by oral prednisolone (20 mg/day). After the steroid therapy was started, the left abducens nerve palsy and CSF findings improved. During the course of tapering steroid therapy, serum PR3-ANCA and CSF IL- 6 levels decreased. Four months after symptom onset, the left abducens nerve palsy was completely resolved with treatment of oral prednisolone (10 mg/day). CSF, cerebrospinal fluid; mPSL, methylprednisolone; PSL, prednisolone.

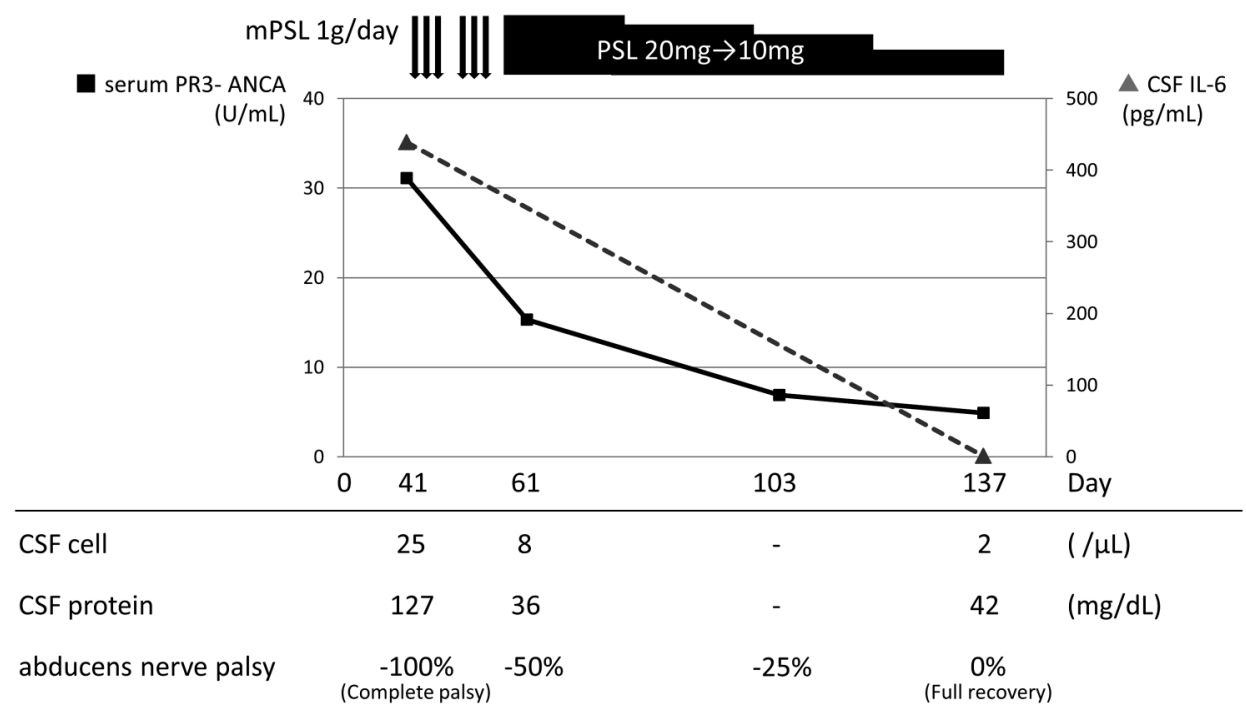

Table 1 Case reports of cranial nerve disorder associated with UC

\begin{tabular}{|c|c|c|c|c|}
\hline Author & Cranial nerve lesion & Suspected mechanism & Treatment & Clinical course \\
\hline Steinbach et $a l^{5}$ & Olfactory nerve & Autoimmune & NA & NA \\
\hline Alexandre et $a l^{6}$ & Optic nerve & $\begin{array}{l}\text { 1. Autoimmune } \\
\text { 2. Anti-TNF therapy associated }\end{array}$ & $\begin{array}{l}\text { 1. Steroid } \\
\text { 2. Steroid }\end{array}$ & $\begin{array}{l}\text { Improvement } \\
\text { Improvement }\end{array}$ \\
\hline Present study & Abducens nerve & Autoimmune & Steroid & Improvement \\
\hline Gondim Fde et $a l^{7}$ & Facial nerve & NA & NA & NA \\
\hline Kumar et $a l^{8}$ & Vestibulocochlear nerve & Autoimmune & Steroid & Improvement \\
\hline Kawashima et $a l^{9}$ & Hypogrosal nerve & Autoimmune & Steroid & Improvement \\
\hline
\end{tabular}




\section{Learning points}

- Neurological disorders associated with UC are uncommon.

- Neurological disorders associated with UC may occur independent of the UC activity.

- We describe a case of unilateral abducens nerve palsy associated with PR3-ANCA-positive UC, where serum PR3-ANCA levels and neurological symptoms improved simultaneously during the course of tapering steroid therapy.

- Serum PR3-ANCA level may have been a useful parameter of the neurogenic complications accompanying ANCA-positive $U C$ in the present case, although the pathogenic role of PR3-ANCA in UC remains unknown.

Contributors YK is a major contributor in writing the manuscript. DY and TU also treated the patient and interpreted the patient data. All authors read and approved the final manuscript.

Competing interests None declared.

Patient consent Obtained.

Provenance and peer review Not commissioned; externally peer reviewed.

Open Access This is an Open Access article distributed in accordance with the Creative Commons Attribution Non Commercial (CC BY-NC 4.0) license, which permits others to distribute, remix, adapt, build upon this work non-commercially, and license their derivative works on different terms, provided the original work is properly cited and the use is non-commercial. See: http://creativecommons.org/ licenses/by-nc/4.0/

\section{REFERENCES}

1 Mahler M, Bogdanos DP, Pavlidis P, et al. PR3-ANCA: a promising biomarker for ulcerative colitis with extensive disease. Clin Chim Acta 2013;424:267-73.

2 Arias-Loste MT, Bonilla G, Moraleja I, et al. Presence of anti-proteinase 3 antineutrophil cytoplasmic antibodies (anti-PR3 ANCA) as serologic markers in inflammatory bowel disease. Clin Rev Allergy Immunol 2013;45:109-16.

3 Bartůnková J, Tesar V, Sedivá A, et al. Diagnostic and pathogenetic role of antineutrophil cytoplasmic autoantibodies. Clin Immunol 2003;106:73-82.

4 Casella G, Tontini GE, Bassotti G, et al. Neurological disorders and inflammatory bowel diseases. World J Gastroenterol 2014;20:8764-82.

5 Steinbach S, Reindl W, Dempfle A, et al. Smell and taste in inflammatory bowel disease. PLOS ONE 2013:8:e73454.

6 Alexandre B, Vandermeeren $Y$, Dewit 0 , et al. Optic neuritis associated or not with TNF antagonists in patients with inflammatory bowel disease. J Crohns Colitis. 2016; 10:541-8

7 Gondim Fde A, Oliveira GR, Teles BC, et al. A case-control study of the prevalence of neurological diseases in inflammatory bowel disease (IBD). Arq Neuropsiquiatr. 2015;73:119-224.

8 Kumar BN, Smith MS, Walsh RM, et al. Sensorineural hearing loss in ulcerative colitis. Clin Otolaryngol Allied Sci 2000;25:143-5.

9 Kawashima K, Ishihara S, Doi K, et al. Ulcerative colitis associated with isolated unilateral hypoglossal nerve palsy. Intern Med 2012;51:3135-7.

10 Colombel JF, Sands BE, Rutgeerts $P$, et al. The safety of vedolizumab for ulcerative colitis and Crohn's disease. Gut 2016. doi:10.1136/gutjnl-2015-311079

11 Scheid R, Teich N. Neurologic manifestations of ulcerative colitis. Eur J Neurol 2007; 14:483-93.

12 Losses A, River Y, Eliakim A, et al. Neurologic aspects of inflammatory bowel disease. Neurology 1995;45:416-21.

Copyright 2017 BMJ Publishing Group. All rights reserved. For permission to reuse any of this content visit

http://group.bmj.com/group/rights-licensing/permissions.

BMJ Case Report Fellows may re-use this article for personal use and teaching without any further permission.

Become a Fellow of BMJ Case Reports today and you can:

- Submit as many cases as you like

- Enjoy fast sympathetic peer review and rapid publication of accepted articles

- Access all the published articles

- Re-use any of the published material for personal use and teaching without further permission

For information on Institutional Fellowships contact consortiasales@bmjgroup.com

Visit casereports.bmj.com for more articles like this and to become a Fellow 